\title{
Disparity between Fusion Center Web Content and Self-Reported Activity
}

\author{
Jeremy G. Carter, Ph.D. ${ }^{1}$ \\ School of Public and Environmental Affairs \\ Indiana University - Purdue University Indianapolis, USA \\ Carla Lewandowski, Ph.D. \\ Law and Justice Studies \\ Rowan University, USA \\ Gabrielle A. May \\ School of Public and Environmental Affairs \\ Indiana University - Purdue University Indianapolis, USA
}

\begin{abstract}
The fusion center literature is limited and lacks consensus regarding operational focus and strategic priorities. Perhaps the lone consistent finding in this literature is the lack of awareness among outsiders regarding what fusion centers do and the capabilities they provide. Contemporary communication research indicates the Internet serves as the primary source of information to inform what they do not understand. The present study employs a mixed methods approach that combines a content analysis of fusion center web content with fusion center self-report data gleaned from a federally funded project. This study encompasses 74 of the 77 primary and officially recognized fusion centers in the United States. Results indicate that centers provide limited information online about their organization and significantly under-report their activities and capabilities online in comparison to self-reported tasks. Information available online through official fusion centers websites is poor at best. Fusion centers self-report to engage in tasks consistent with their information sharing and analytic mission. A context for the findings is provided, in addition to recommendations and study limitations.
\end{abstract}

\section{Keywords}

Fusion center, Intelligence, Information sharing, Content analysis

\section{Citation}

Carter, J. G., Lewandowski, C., \& May, G. (2016). Disparity between fusion center web content and self-reported activity. Criminal Justice Review, 41(3), 335-351.

\section{Link}

http://cjr.sagepub.com/content/41/3/335

\footnotetext{
${ }^{1}$ Corresponding author: 801 W. Michigan Street, BS 4081, Indianapolis, IN 46202, Phone: 317-274-4170, carterjg@iupui.edu
} 


\section{Disparity between Fusion Center Web Content and Self-Reported Activity}

\section{Research Purpose}

Fusion centers represent one of the most observable structural change in policing postSeptember 11, 2001. At the time of this study, the U.S. Department of Homeland Security officially recognized 77 fusion centers throughout the United States. ${ }^{1}$ Despite their having received substantial resources and serving as a critical source of terrorism and crime information for all levels of law enforcement, little is known about these centers. When ambiguity surrounds something of interest in contemporary society, law enforcement and the general public often rely upon information gathered from the Internet to develop a sense of understanding. Unfortunately, this information - even from an organization's official website - may not be all-inclusive and representative of the organization. As a result, the perceptions developed by law enforcement and the general public based on this information may be inaccurate and can lead to declines in perceived legitimacy and limitations of functional capability.

Put simply, outsiders may perceive fusion centers to be of limited value and may not seek to interact with a fusion center in light of this perception. Though the research evidence regarding fusion centers is sparse, a common finding is that law enforcement personnel as well as the general public are unaware of fusion center capabilities and that fusion centers desire a capacity to market their resources and mission information. The present study examines online content within official websites, or webpages, from each of the primary and secondary fusion centers in the U.S. and compares this content with data collected from the centers as part of a federally funded project. This approach allows for a comparison of self-reported fusion center activity (i.e., what they are doing) and web-based information intended to inform outsiders of fusion center capabilities. 
Results suggest that fusion centers are under-communicating their operations and contributions to the law enforcement community.

\section{Relevant Research}

Evolution of Fusion Centers

Fusion centers are brick-and-mortar entities comprising representatives primarily from federal, state, and local law enforcement agencies as well as members of the private sector and public works. In theory, this diverse composition of organizations is best positioned to identify and understand threats facing a particular jurisdiction or region. The premise of fusion centers is that information analyzed from diverse sources results in more accurate intelligence (Clark, 2007) through a "fusion" process resulting from analyzed raw intelligence provided by the disparate organizations (Carter \& Carter, 2009a). Dissemination of intelligence products to relevant stakeholders brings the intelligence fusion process full circle and helps to ensure that fusion centers do not operate as silos of information (Carter \& Carter, 2009b; Ratcliffe, 2008). Each jurisdiction has distinctive and diverse needs. As a Congressional Research Service report stated, “There appears to be no 'one-size-fits-all' structural or operational model for fusion centers” (Rollins, 2008, p.18). In fact, a large number of centers have undergone changes since their inception in order to meet the needs of their constituents.

Despite the change in focus and specified guidelines and standards to focus fusion center operations (Global Intelligence Working Group, 2005; Global Intelligence Working Group, 2008), operational gaps and quantifiable knowledge remain missing from the discussion of fusion center research. Although the body of literature on fusion centers is growing, more rigorous studies regarding their activities are sorely needed. Many of the operational and strategic concerns about 
fusion centers may be derived from the mission shift from counter-terrorism to all-crimes, allhazards, all-threats. The lack of evidence and dynamic operational focus has led to speculation of their ineffectiveness (General Accountability Office, 2007; Taylor \& Russell, 2012; U.S. Senate, 2012) and legality (German \& Stanley, 2008; Masse \& Rollins, 2007; Monahan \& Palmer, 2009).

The Intelligence Reform and Terrorism Prevention Act of 2004 articulated the necessity for law enforcement to broaden its intelligence focus to include threats other than terrorism, as criminal and disaster threats were seen as more likely to inflict damage within U.S. communities. This modification yielded a necessary change in 1) the assessment of information needs for fusion centers, and 2) the need for fusion centers to communicate their function appropriately to other law enforcement agencies, community organizations, and citizens. Thus, from an outsider's perspective, it is imperative to have access to a clear and accurate description of fusion center resources and activities.

\section{Limited Fusion Center Evidence}

Few scholars have gained access to fusion centers and begun to examine the intelligence process within these organizations. These studies have focused largely on analytic capabilities and information sharing activities in the form of information gathering, dissemination, and types of relationships. Graphia-Joyal (2010) employed a qualitative study that included 49 interviews at four fusion centers in the northeast region of the U.S. Her study concluded that centers had yet to develop a robust analytical capability. Rather, they had been providing investigative case support that lacked analysis to inform operational, tactical or strategic action (the goal of intelligence analysis). With respect to information gathering, a quantitative survey of local law enforcement personnel in South Carolina illustrated the utility of the state fusion center and noted rather positive 
responses (Cooney, Rojek \& Kaminski, 2011). Ratcliffe and Walden (2010) examined the volume and frequency of information that flowed from local law enforcement to the state fusion center. They concluded that $48 \%$ of New Jersey troopers had not communicated with the fusion center through any mechanisms and that many of the troopers sent information only because they believed it would help their investigation - not because it could have implications for terrorism or other criminality.

Perhaps the efficacy of a fusion center may best be captured through the dissemination of intelligence products and the utility of those products for stakeholders. Cooney, Rojek, and Kaminski (2011) noted that 75\% of the police executives found the center to be moderately useful or very useful. Conversely, Ratcliffe and Walden (2010) found that more than half (58\%) of the troopers surveyed had not used intelligence disseminated by the fusion center in the previous six months. A general sense of the applicability of fusion center products to end-user operations may be challenging given the diversity of end-user needs. Consumers of fusion center products and resources are highly varied. This is both a strength and weakness of the fusion center model as these centers are designed to promote information and intelligence sharing across disparate organizations, but this organizational variation creates hurdles for centers to tailor analytic products. For example, in his national survey of fusion centers, Carter (2015) noted that these centers have relationships with organizations that include every level of law enforcement, public health, public works, the private sector, the military, and even educational institutions. Creating a single product that meets specific needs for all these entities is likely unrealistic and beyond the resource reach of many centers.

Lastly and salient to the focus of this research, some scholars have recognized that law enforcement may not understand the utility of fusion centers because the centers need to be more 
proactive in marketing themselves. Studies have noted that the centers do a poor job of communicating their analytic services (Chermak et al., 2013; Graphia-Joyal, 2010) and data availability (Carter \& Chermak, 2012). Ratcliffe and Walden (2010) acknowledged that educating local law enforcement is a necessary function for the fusion centers so that consumers understand how to use and contribute to intelligence products. In a similar vein, Cooney et al. (2011) found that personnel who had received training about a fusion center's capabilities were more likely to rate the center as useful.

In sum, the sparse literature to date on fusion centers has lacked consensus regarding the activities these centers perform as well as their efficacy and utility to enhance local law enforcement intelligence. There does appear to be agreement on the need for fusion centers to communicate their capabilities and intent more clearly. Web-accessible information is the medium through which outside persons gain an understanding and awareness of things they do not comprehend (Case, 2012). As such, this study seeks to inform this research shortcoming by examining web content from each of the primary and officially recognized fusion centers in the U.S. This information is combined with self-report survey data to illustrate the accuracy of webaccessible information and, thus, the information outsiders process to learn about fusion centers.

\section{Methods}

This study employs a mixed methods approach to explore the congruence between the goals and purposes fusion centers communicate to the public and the activities in which they report to engage. Content analysis of websites and webpages is coupled with self-report survey data from a national project. The intent of this data comparison is to illustrate the divergence between what fusion centers communicate to outsiders and the activity in which they self-report to engage. 
Capturing this divergence is important given the current literature agrees that few outsiders understand fusion centers and that fusion centers desire an ability to market their resources. In a study similar to the present research, DeLone (2007) assessed mission statements from the 50 largest police departments in the U.S. to gauge the extent to which these departments had incorporated a reference to terrorism following the 9/11 terrorist attacks. A portion of DeLone's research examined dimensions of police department competencies, measured in the form of community policing or fear of crime, as these dimensions were seen as critical to the contemporary tasking of municipal police. The present research follows in a similar vein with a focus on the core competencies of fusion centers.

\section{Web Content Analysis}

The focus of the present research is on four dimensions of fusion center core competencies. These dimensions were derived from two operational documents, co-published by the U.S. Department of Justice and the U.S. Department of Homeland Security, that serve as the developmental models for fusion centers: the Fusion center Guidelines (Global Intelligence Working Group, 2005) and the Baseline Capabilities for State and Major Urban Area Fusion Centers (Global Intelligence Working Group, 2008). These dimensions, each of which has multiple traits, target the key function fusion centers provide to law enforcement - facilitating the sharing and analyzing of information to prevent threats. The four dimensions of core competencies include:

1. Relationships: Specific reference to having relationships with law enforcement, other public services, and private sector organizations for purposes of sharing and collecting information. 
2. Information Collection and Sharing: Specific reference to facilitate the collection and sharing of information.

3. Analysis: Specific reference to analyzing information and/or providing analytic resources.

4. Areas of Emphasis: Specific reference to a threat type or operational focus.

A list of fusion centers for inclusion in the present study was retrieved from the U.S. Department of Homeland Security's official website, which provides names and contact information for each of the primary ${ }^{2}$ and recognized fusion centers (U.S. Department of Homeland Security, 2015). Regional crime analysis and real-time crime centers are not included in the present study due to their different operational function as compared to fusion centers. Only fusion centers recognized by the U.S. Department of Homeland Security are included in the study. Websites and webpages were accessed via open source Internet searches. Websites and webpages varied dramatically across the fusion centers included in the study. Some fusion centers had a dedicated and comprehensive website whereas others were limited to a single webpage hosted on another agency's website (typically the managing agency). Only information available within an official website of webpage was reviewed and analyzed for the present study. Though additional information about fusion centers may be available from other sources online, the validity of such information cannot be verified. Information retrieved from official content pages is assumed to be the most valid and representative of the fusion center's capacity.

Prior to reviewing the web content, a list of traits was operationalized consistent with government recommendations in the two aforementioned federal documents. The researchers discussed each trait's operational definition to ensure a consistent understanding and recognized the unit of analysis as the fusion center organization. As a group, the research team reviewed 
varying websites and webpages to ensure consistency across navigation of the content. All hyperlinks and available content, including documents posted to websites, was navigated to best capture all available information. Each researcher independently reviewed web content and coded the observed traits based on the written coding protocol. Coded data was then compared among the researchers and any differences in coding interpretation were reviewed until consensus was reached regarding the most appropriate coding of a trait. Traits were grouped in dimensions based on the narrative context in which the trait was mentioned within the web content. For example, the trait “community” was coded to capture a working rapport with the community. Instances in which other indicators were used to signal the trait of interest were also captured and coded. For example, the statement "The fusion center seeks to collaborate proactively with citizens to share information,” would be coded in the affirmative as a reference to "community." If a trait was mentioned outside of an appropriate context, it was excluded from the analysis. For example, the statement “The fusion center works directly with the law enforcement community” would not be captured as a reference to the desired trait.

The web content sample includes 74 of the 77 officially recognized fusion centers. The Puerto Rico National Security State Information Center, the Mariana Regional Fusion center (Guam), and the U.S. Virgin Islands Fusion center are excluded due to their lack of available information. The fusion centers included in the web content sample were designated predominantly as primary centers (66.2\%). Roughly half had another fusion center in the same state (52.7\%) and identified themselves as focusing on "all-threats, all-hazards" (55.4\%). Table 1 lists the fusion centers included in the web content analysis.

[ Table 1. Fusion centers included in the study $(n=74)$ approximately here ] 
Survey of Fusion Centers

Self-report data were gleaned from a larger project ${ }^{3}$ and include responses from 96 fusion center personnel representing 72 fusion centers. The survey sample of fusion center respondents comprised of persons who attended the National Fusion Center Conference (NFCC). Attendees of the NFCC include fusion center directors, administrators, and upper-level operational personnel. This sampling strategy, which includes nationally representative fusion center personnel, was chosen for three reasons. First, in attending this conference, these persons were identified by their respective fusion center as a key representative of their organization. Second, as a result of their selection on behalf of their center, this sample includes personnel who have a working knowledge of key issues tied to their fusion center and its intelligence capacity. Thus, these persons are best able to address the organizational capacity of their centers. Third, these persons' awareness of the contemporary intelligence structures, requirements, and formal communication networks involved in fusion centers increases the likelihood that they will have direct knowledge about the strengths and weaknesses of these issues. This sampling approach to target key knowledgeable personnel in law enforcement organizations has been utilized in police research focused on specialty personnel when examining similar contemporary issues, such as police assigned to cybercrime (Bossler \& Holt, 2012; Holt \& Bossler, 2012).

Table 2 displays descriptive information of the fusion centers represented in the current study. Responses were reported predominantly by administrators and supervisors. This is beneficial to the validity of the responses, as these persons are most likely to have an accurate perception of the activities that occur within the center. The modal response category for tenure at the fusion center was one to three years at the time the survey was conducted. This is not outside the norm, given the nature of turn over within fusion centers as agencies rotate assigned personnel. 
In the case of newly assigned personnel, having been assigned to the fusion center for only one to three years may not be indicative of a lack of knowledge, since assigned personnel are typically chosen as a result of their experience in intelligence operations within their home agency.

[ Table 2. Fusion center Respondent Descriptives $(\mathbf{n}=\mathbf{9 6})$ approximately here ]

Web content traits were matched with survey items in similar contexts. For example, within the web content dimension focused on relationships for information sharing, the "community" trait was present in the statement "The fusion center seeks to establish a two-way communication channel with the community to collect and disseminate terrorism related information.” This trait was matched with the survey item question "How close is your working relationship with the public community?" Likert responses to this item included "Very close," Somewhat close," "Distant," and "We have no relationship." Responses in the affirmative - "Very close” and "Somewhat close" - were included as being representative of this trait.

\section{Sample Comparisons}

Fusion center characteristics are presented in Table 3 for purposes of comparison between the two samples. Overall, the two samples were rather similar across the available metrics. Just over half of both the web content (55\%) and survey (57\%) centers self-identified as focusing on “all-crimes, all-hazards, all-threats” - implying a diverse set of intelligence related operations that go beyond the scope of terrorism. A relatively small percentage of centers from both samples selfidentified as focusing solely on terrorism. This is not surprising, as many centers rely on resource support from multiple entities that have varied operational interests, as well as state funding 
mandates that guide a focus on more general public safety issues. On a related note, each state varies with respect to the organization that serves as the chief operating entity. The majority of fusion centers within both samples indicated operation by the state police (55\% of web content centers and 57\% of surveyed centers). The remaining centers reported a similar proportion of operating entities.

\section{[ Table 3. Sample Comparison approximately here ]}

\section{Findings}

Findings are reported and presented in figure format with corresponding tables below. Valid percent is presented along the X-axis. Given organizational anonymity of fusion centers in the self-report survey (each fusion center was assigned a unique identifier), linking web content data to the self-report survey data was not possible. In order to explore if observed differences between the two samples were statistically significant, two-sample t-tests (two-tailed) were employed to examine mean differences between traits across each sample methodology. ${ }^{4}$ This method was conducted using the t-test calculator (also called the mean-comparison test calculator) for summary data in STATA (IC version 14) using the mean, standard deviation, and sample size for each observed trait within each sample. Though the use of this procedure with categorical variables is less-than ideal, it provides additional insights into the observed differences between self-reported activity and information conveyed via websites beyond the substantive differences illustrated by the descriptive statistics reported.

In their most simplistic form, fusion centers are designed to facilitate information sharing, analysis, and threat prevention and mitigation through inter-organizational collaboration. The 
dimensions identified for this research follow in a similar vein. Figure 1 presents comparisons of web content traits and survey data items pertaining to relationships for information sharing. To begin, each dimension of relationships for information sharing from survey respondents differed significantly from information presented online. Not surprisingly, the majority of fusion center web content (63\%) indicated having relationships with police to share information. Community and private sector relationships were equally present (42\%). Noticeably fewer centers indicated seeking relationships with first responders and public health organizations. When compared to the web content sample, survey respondents indicated a stronger presence of relationships across each of these traits. More than 90 percent of survey respondents indicated having relationships with police. While this number is high (especially when compared to the web content sample), it is also somewhat questionable as to why this frequency is not larger given the role of fusion centers to work directly with police.

[ Figure 1. Fusion center Relationships for Information Sharing approximately here ]

Further analyses indicate survey respondents that self-report High Intensity Drug Trafficking Areas (HIDTA) and Military as their main operating entity have distant relationships with the police. This same trend is present among web content as those identifying as HIDTA- or Military- operated do not make reference to relationships with police. Unfortunately, the available data do not allow for a more refined exploration and this finding should likely be the focus of future research inquiries in this area. Relationships with first responders (mean difference of .63, $t$ $=11.042$ ) and public health (mean difference of $.55, t=5.441$ ) represent the most significant difference in the traits, with web content substantially under-reporting these relationship areas 
compared to the self-report data. Interestingly, four of the five fusion centers that indicated working with public health were recognized fusion centers as opposed to primary centers. This may be related to the nature of recognized centers, which are typically more location centric and focus specifically within their immediate geography. Primary centers, conversely, are responsible for statewide issues.

Operational tasks likely to result from the above relationships are traits that pertain to information sharing and collection. Figure 2 displays traits associated with this operational dimension. Most notably there was a rather large and significant difference between self-report and web content pertaining to suspicious activity reporting (mean difference of $.70, t=14.803$ ) also known as "See Something, Say Something.” Unfortunately the data do not allow for this difference to be examined across organizational characteristics that may shed light on why this difference is observed. This finding is unexpected, as the Nationwide Suspicious Activity Reporting Initiative, spearheaded by the U.S. Department of Homeland Security and the Federal Bureau of Investigation among others, has received a great deal of attention and substantial resources across the country. Even more perplexing is that SARs are designed to be driven by both police and the public. It seems reasonable to assume that fusion centers should project the importance of SARs through their websites to inform community members of the effort and to solicit any information the latter may be able to provide. Specific reference to information sharing $(t=5.083)$ and information collection $(t=2.181)$ also differed significantly across the two samples. Though different, the descriptive data demonstrate that fusion centers frequently identify these dimensions. This is a welcomed finding as the sharing and collection of information is vital to the fusion center mission (Global Intelligence Working Group, 2005). Related to this mission, there was no difference observed between self-report and web content samples regarding intelligence 
dissemination. Though welcomed, given these traits are likely the "heart" of fusion center activity, it is somewhat interesting to find that roughly a quarter of the centers made no web content reference to these traits.

[ Figure 2. Information Collection and Sharing approximately here ]

Moreover, findings from the survey respondents lend some insight with regard to the extent these operational traits are actually occurring within centers across the country. This is especially welcome with regard to SAR as more than 80 percent of centers noted having a formal SAR program. Every survey respondent indicated engaging in information sharing, a welcomed and expected finding. Somewhat fewer indicated they engage in information collection (86\%) and intelligence dissemination (77\%). The former finding could be explained by some fusion centers perceiving information as being "pushed to them" as opposed to actively collecting information (Carter \& Chermak, 2012). The latter finding is more perplexing, as fusion centers are tasked with sharing information, in particular distributing analytic products to partners and subscribers. Further analyses of survey respondents that indicated they do not disseminate intelligence are largely isolated to those operated by HIDTA, Military, and State Bureaus of Investigation. These centers may have unique tasking that limits the information they disseminate to others and thus could potentially influence survey respondent perceptions of intelligence dissemination. Again, a refined exploration of this issue is beyond the scope of the data and should be considered in future research.

The analysis of raw information may arguably be the most critical function fusion centers provide in the greater law enforcement intelligence landscape. Aside from analyzing raw 
information and connecting disparate pieces of information and intelligence, the centers also provide an analytic resource for agencies that do not have this capability (Carter \& Carter, 2009b). Figure 3 presents the frequency of analytic traits in both samples. Overall, findings indicate significant differences between samples across each analysis dimension. Notably, intelligence analysis $(t=19.251)$, process information $(t=14.046)$, and integrate information $(t=11.004)$. The general absence of these dimensions on fusion centers' web pages is somewhat discouraging. As noted previously, research has found that fusion centers wish to market and communicate their mission and capabilities to outsiders to enhance fusion center effectiveness and inform knowledge gaps among both law enforcement and the general public. The findings presented here illustrate that fusion centers are failing to identify these capabilities on their web pages and are thus unlikely to be best communicating this information. This is especially true with respect to intelligence analysis - the focal capacity of fusion centers - as only eight percent of web pages indicated this dimension.

\section{[ Figure 3. Analysis Properties approximately here ]}

More promising is the frequency at which survey respondents self-reported their fusion center to be engaged in these dimensions of analysis. Evaluation, information processing, information integration, intelligence production, and intelligence analysis are all above 83 percent with the latter approaching 98 percent. Crime analysis is the lower-bound outlier in this dimension, with only 55 percent of centers indicating they engage in this activity. These frequencies may speak to the nature of simplicity, or conciseness, within web content. Most fusion center web content (82.4\%) included a reference to intelligence analysis, with a substantial decrease in the other analytic traits. The inclusion of intelligence analysis in fusion center web content differed 
significantly from the other analytic traits. This decrease could be explained by the fact they are considered to be specific tasks in the process of intelligence analysis. Intelligence products, integration, evaluation, and process are all components of what is known as the "intelligence cycle" (Carter, 2009). It is likely that when composing web content, the inclusion of the term "intelligence analysis" may be viewed as encompassing all of these other traits. This could also explain why these frequencies were noticeably higher among the survey respondents, as fusion centers are engaging in the processes representative of intelligence analysis.

Finally, a rather broad dimension was explored regarding areas of emphasis for fusion centers. There is ambiguity regarding what the centers should focus on (Taylor and Russell, 2012: U.S. Senate, 2012) and the threats they attempt to prevent and mitigate (Carter, 2015). These centers have also come under criticism regarding civil liberties (German and Stanley, 2008; U.S. Senate, 2012) and pressure to serve as a source of training for local law enforcement (Carter et al., 2013). This range of issues serves as the catalyst for information provided in Figure 4 and are grouped as "threats" and "operations" areas of emphasis. In terms of threats, public health $(t=$ 9.829) and threats $(t=9.463)$ (survey respondents indicating a focus on general threats in their jurisdiction and web content reference to general threats) different most significantly across samples.

The lack of public health as a threat focal point is unclear. Previous research has speculated that fusion centers are hesitant to engage public health issues, given the complexities associated with the HIPAA laws and the burden of managing such information (Carter \& Rip, 2013). It should also be noted that the emphasis on public health within fusion centers did not gain official recognition until 2011, when the U.S. Department of Homeland Security published a supplement to the baseline capabilities guidelines that specifically focused on public health concerns (U.S. 
Department of Homeland Security, 2011). This late onset may explain the lack of a public health presence in fusion center web content. Perhaps, even more simply, fusion centers had not updated their web content since their inception. Mechanisms for improved information sharing and intergovernmental collaboration to best prevent and mitigate public health related threats should serve as the basis for future research efforts. It is rather unexpected to find less than half (44.6\%) of the fusion centers used the term "threat" in their web content, given the emphasis laid out in the two federal guidelines. The remaining threat types were not frequently present. No significant difference was observed between samples regarding crime, with both self-report (76\%) and web content (70\%) indicating approximately the same frequency. Also worth noting is that this majority emphasis on crime perhaps illustrates an operational gap as only 56 percent of survey respondents and 23 percent of web content indicated the fusion center having the capacity to engage in crime analysis (as reported in Figure 3 above).

[ Figure 4. Areas of Emphasis approximately here ]

With respect to operations, emergency management $(t=11.636)$ and training $(t=10.865)$ differed most significantly across samples. Further analysis of centers indicating a focus on these operations failed to yield any insightful trends. Affirmative responses were noted in primary and recognized centers - those operated by state police, municipalities, and state homeland security. The lone common characteristic of these centers was self-identification as "all-crimes, all-hazards, all-threats” centers. Perhaps aiding in the explanation of the high rate of survey respondents indicating they focus on emergency management and training is that many fusion centers receive their primary operational funding from their state’s emergency management budget to co-serve as 
not only a fusion center, but also an emergency operations center during times of crisis (U.S. House of Representatives, 2013). In this role, fusion centers also provide training to local partners for purposes of crisis management. In a similar vein, it is surprising that few survey respondents (21\%) and web pages (11\%) indicated preparedness as an operational focus given the role of preparedness in emergency management (a difference that was non-significant across samples).

No significant difference was observed across samples regarding civil liberties. Roughly half (53\%) of survey respondents indicated civil liberties as a focus while reference to civil liberties appeared in only 40 percent of the fusion center web content. This percentage is lower than expected, given the substantial amount of public scrutiny surrounding fusion centers and the perception of retaining identifiable information on citizens without the establishment of a criminal predicate. Perhaps more surprising is that web content available on the Internet should serve as an ideal communication medium to present organizational concern for civil rights and the extent to which the fusion center is observing such rights. The results presented here indicate that few centers have taken advantage of communicating this message or may be pursuing this effort through other means.

While the frequency of self-reported emphasis on civil liberties represents a more positive outlook when compared to figures reported by the U.S. Senate (2012) and U.S. Government Accountability Office (2010), it is lower than anticipated. What makes this frequency even more surprising is the nature of the question and the belief it would draw a socially acceptable response, as fusion centers would be hesitant to answer in the negative. This is especially true given the respondents were largely administrators (51\%) and supervisors (20\%). Additional analysis yielded no differences across centers responding in the affirmative versus negative. These findings should not be taken as evidence of omission on behalf of fusion centers. A report from the U.S. House of 
Representatives (2013) found strong compliance with the protection of civil liberties among fusion centers studied.

\section{Discussion and Conclusion}

The findings presented here indicate there are significant differences between the information fusion centers provide to the public via their web content and the activities fusion center personnel self-report. Put simply, fusion centers are short selling their contribution to the law enforcement intelligence landscape. Moreover, not only are the activities reported by fusion centers significantly more present than portrayed by the centers' web content, but the information generally available on the centers' websites or webpages is rather minimal. The present study's observation that fusion centers do a generally poor job of communicating their mission, resources, and capabilities to both law enforcement and the public via the internet is insightful.

Research has shown that fusion centers indicate frustration with garnering support and participation from external law enforcement agencies and desire to market their resources and capabilities to the law enforcement community (Graphia-Joyal, 2010; Carter et al., 2013; Ratcliffe \& Walden, 2010). Moreover, fusion centers have been the focus of criticism resulting from a lack of clear operational priorities (Taylor \& Russell, 2012; U.S. Senate, 2012) as well as scrutiny from the general public regarding concerns of privacy violations (German \& Stanley, 2008; Monahan \& Palmer, 2009; U.S. Senate, 2012). Given the role webpages play in communicating information to the public in contemporary society, fusion centers' official webpages serve as an initial point of information gathering and thus are positioned to remedy the aforementioned concerns if done so

properly. Unfortunately, it appears fusion centers are not adequately utilizing their webpages to effectively communicate information. This forces both law enforcement and the general public to 
draw inferences about fusion centers based on insufficient information or from other sources that may be less favorable toward the centers.

A recommendation from this research would be for the fusion centers to better communicate their capabilities and activities to the public via their web presence. This would not only close this communication gap, but could also produce substantial information gains as external organizations may be more willing to push information to the centers once the information's intent was understood. This clarity may also enhance the functional capability of fusion centers as they rely upon information flow to and from local partners. This lack of communication regarding "what fusion centers do" is consistent with the limited previous research in this area that concluded one of the most pressing needs for fusion centers was to market their capabilities (Graphia-Joyal, 2010; Carter et al., 2013; Ratcliffe \& Walden, 2010).

The present study provides evidence that fusion centers should extend the need for marketing to the general public, rather than just the law enforcement stakeholders. This is all the more pressing given the negative publicity that fusion centers have received in recent years (German \& Stanley, 2008; Monahan \& Palmer, 2009). It may be due to this publicity that fusion centers have felt the need to divulge as little information as possible, but this strategy leaves fusion centers vulnerable to the thoughts of the American public still weighing the cost of security in terms of violations of privacy.

Of the analytic traits explored from the web content, less than a quarter of the fusion centers made reference to crime analysis, which was also the analytic function least reported by the survey respondents. Despite the centers acknowledging an "all-crimes, all-hazards, all-threats” model of operation, intelligence analysis should be their driving analytic capability. Put simply, the differences between crime analysis and intelligence analysis are nuanced (Carter, 2012). A 
pragmatic reality is that state and local law enforcement agencies are tasked with combating crime. Thus, the analytic products they need should focus on this mission. By utilizing methods and sources of information from both analytic methods, fusion centers can best position their resources to meet consumer needs and have the most direct impact on preventing crime and terrorism.

\section{Limitations and Future Research}

The temporal convergence of the survey data and web content was not synchronous. Survey data was collected from 2009-2010 while web content analyses were conducted from 20142015. Though not perfectly aligned, this temporal gap may not be as troublesome as it appears. Many websites and webpages lacked up-to-date content. Approximately $40 \%$ of the websites and webpages had a copyright date or content update data older than 2013 (ranging from 2011-2013). Moreover, the disparity illustrated here is that fusion centers under-report their activities online. It is reasonable to assume that self-reported activity will not decrease as a fusion center matures. Even though the focal priorities of such centers may change in this time frame, the mission shift of fusion centers largely occurred in 2005 and 2006 and has remained constant since. This shift occurred prior to the survey data being collected and thus the survey data are likely to be in alignment with contemporary fusion center operations.

As noted in the description of the samples, survey respondents varied in position within their centers. This could be viewed as a strength as the results could reflect the input of individuals at various levels of the organization. It could also be viewed as a weakness, as the functions performed by individuals in various positions could, and likely do differ. For instance, analysts 
may report an emphasis on the actions in which they engage, while administrators report that they do something much different. This issue is rather common in organizational policing research and is viewed as more of a strength than weakness as the current study relies upon insight from all levels of the organization (Andrews et al., 2008; Burruss \& Giblin, 2014; King, 2000; 2009; Maguire \& Uchida, 2000). Nonetheless, it is a complexity of the current research that requires acknowledgement to guide future works in this area.

Finally, matching web content traits to survey items was less than pristine. Ideally, survey items would have been constructed to capture respondents' perceptions of a center's activities that are consistent with its mission, capabilities, and competencies, as articulated in the two guiding documents used in the present study. Survey items and web content traits were matched as best possible to capture the appropriate contexts for both. If a web content trait or survey item was of interest but lacked an appropriate comparison item, it was not included in the present study. Relatedly, the unit of analysis in the present study is fusion center organizations and the survey data are self-reported by an individual within the fusion center on behalf of the organization. Though this approach is rather common in policing research, especially in the context of positions that require specialized knowledge, it is nonetheless a limitation.

To the authors' knowledge, this study is one of the first in criminology and criminal justice to utilize a methodology that compares web content to self-reported organizational activity. Given the salience of web content as a medium for communication in contemporary society, scholars should seek to further utilize this approach in other areas of criminal justice. As an example, this approach may be insightful for identifying mechanisms to improve communication between the police, correctional reentry programs, mental health services, and/or court processes and the general public who may visit such websites to retrieve information on the criminal justice system 
or process. Scholars should also seek to explain the significant differences that were observed in the present study, but could not be pursued further due to data limitations.

Future research should seek to quantify more precisely the extent to which targeted stakeholders are unaware of fusion centers' capabilities and potential deliverables. Such an investigation could provide a more granulated illustration about which components are most ambiguous for fusion centers stakeholders. Ideally, it would also capture desired stakeholder "wants and needs" that could be mapped to the availability (or lack) of such capabilities. It may also be possible that certain organizations do not necessarily need to be as informed as others. For example, public health or public works organizations may just need to recognize the importance of actively pushing raw information from their organization to the fusion center, as opposed to needing to know what analytic capabilities can be provided in return. This would help fusion centers avoid inundating their stakeholders with information they do not need. More targeted emails would lead to more careful readings of disseminated intelligence which could potentially spur the flow of information back to the fusion center.

\section{Notes}

${ }^{1}$ For additional information on fusion centers and the National Network of Fusion Centers, visit: http://www.dhs.gov/state-and-major-urban-area-fusion-centers

${ }^{2}$ According to the U.S. Department of Homeland Security (2015, no pagination): "Primary fusion centers serve as the focal points within the state and local environment for the receipt, analysis, gathering, and sharing of threat-related information and have additional responsibilities related to the coordination of critical operational capabilities across the statewide fusion process with other recognized fusion centers. Furthermore, primary centers are the highest priority for the allocation of available federal resources, including the deployment of personnel and connectivity with federal data systems.”

${ }^{3}$ Grant award number 2008-IJCX-0007 from the National Institute of Justice, US Department of Justice. 
${ }^{4}$ A complex survey design in STATA was employed to adjust for clustered responses from respondents within the same fusion center. The most responses from within a single fusion center was three, which occurred for two fusion centers. Ten fusion centers had two respondents while the remaining 70 fusion centers in the study had a single survey respondent. 


\section{References}

Andrews, J., Cameron, H. \& Harris, M. (2008). All change? Managers' experience of organizational change in theory and practice. Journal of Organizational Change Management, 21(3), 300-314.

Bossler, A. M., \& Holt, T. J. (2012). Patrol officers’ perceived role in responding to cybercrime. Policing: An International Journal of Police Strategies \& Management, 35(1), 165-181.

Burruss, G. W. \& Giblin, M. J. (2014). Modeling isomorphism on policing innovation: The role of institutional pressures in adopting community-oriented policing. Crime \& Delinquency, 60(3), 331-355.

Carter, D. L. (2009). Law Enforcement Intelligence: A Guide for State, Local, and Tribal Law Enforcement Agencies (2nd Ed.). Washington, DC: U.S. Department of Justice.

Carter, D. L. (2012). Law enforcement intelligence and national security intelligence: Exploring the differences. IALEIA Journal, 21(1), 1-13.

Carter, D. L., \& Carter, J. G. (2009a). The intelligence fusion process for state, local and tribal law enforcement. Criminal Justice and Behavior, 36(12), 1323-1339.

Carter, D. L., \& Carter, J. G. (2009b). Intelligence-led policing: Conceptual considerations for public policy. Criminal Justice Policy Review, 20(3), 310-325.

Carter, D. L., Chermak, S. M., McGarrell, E. F., Carter, J. G., \& Drew, J. (2012). Understanding the Intelligence Practices of State, Local, and Tribal Law Enforcement Agencies. Final Report 238561. Washington, DC: National Institute of Justice. U.S. Department of Justice.

Carter, J. G. (2015). Inter-organizational relationships and law enforcement information sharing post-September 11, 2001. Journal of Crime and Justice. 38(4), 522-542.

Carter, J. G., \& Chermak, S. (2012). Evidence-based intelligence practices: Examining the role of fusion centers as a critical source of information. In C. Lum and L. Kennedy. (Eds). Evidence-Based Counterterrorism Policy, 65-88. New York: Springer.

Carter, J. G., \& Rip, M. (2013). Homeland security and public health: A critical integration. Criminal Justice Policy Review, 24(5), 573-600.

Case, D. O. (2012). Looking for Information: A Survey of Research on Information Seeking Needs and Behavior (3rd Ed.). Bingley, UK: Emerald Group.

Chermak, S., Carter, J. G., Carter, D. L., McGarrell, E. F., \& Drew, J. (2013). Law enforcement's information sharing infrastructure: A national assessment. Police Quarterly, 16(2), 211244. 
Clark, R. M. (2007). Intelligence Analysis: A Target-Centric Approach $\left(2{ }^{\text {nd }}\right.$ Ed.). Washington, DC: CQ Press.

Cooney, M., Rojek, J., \& Kaminski, R. J. (2011). An assessment of the utility of a state fusion center by law enforcement executives and personnel. IALEIA Journal, 20(1), 1-18.

Darroch, S., \& Mazerolle, L. (2015). Intelligence-led policing: A comparative analysis of community context influencing innovation uptake. Policing \& Society, 25(1), 1-24.

Darroch, S., \& Mazerolle, L. (2013). Intelligence-led policing: A comparative analysis of organizational factors influencing innovation uptake. Police Quarterly, 16(1), 3-37.

DeLone, G. J. (2007). Law enforcement mission statements post-September 11. Police Quarterly, 10(2), 218-235.

General Accountability Office. (2007). Homeland Security: Federal Efforts are Helping Alleviate some Challenges Encountered by State and Local Fusion Centers. No. GAO-08-35. Washington, DC.

German, M., \& Stanley, J. (2008). Fusion center Update. New York, NY: American Civil Liberties Union. Retrieved from http://www.aclu.org/pdfs/privacy/fusion_update_20080729.pdf

Global Intelligence Working Group. (2005). Guidelines for Establishing and Operating Fusion Centers at the Local, State, Tribal and Federal Level. Washington, DC: U.S. Department of Homeland Security. U.S. Department of Justice.

Global Intelligence Working Group. (2008). Baseline Capabilities for State and Major Urban Area Fusion Centers. Washington, DC: U.S. Department of Homeland Security. U.S. Department of Justice.

Graphia-Joyal, R. (2010). Are fusion centers achieving their intended purposes? Findings from a qualitative study on the internal efficacy of state fusion centers. IALEIA Journal, 19(1), 5476.

Holt, T. J., \& Bossler, A. M. (2012). Police perceptions of computer crimes in two southeastern cities: An examination from the viewpoint of patrol officers. American Journal of Criminal Justice, 37(3), 396-412.

King, W. R. (2009). Toward a life-course perspective of police organizations. Journal of Research in Crime and Delinquency, 46(2), 213-244.

King, W. R. (2000). Measuring police innovation: Issues and measurement. Policing: An International Journal of Police Strategies and Management, 23(3), 303-317.

Masse, T., \& Rollins, J. (2007). A Summary of Fusion Centers: Core Issues and Options for Congress. Washington, DC: Congressional Research Service. Report No. RL34177. 
Monahan, T., \& Palmer, N. A. (2009). The emerging politics of DHS fusion centers. Security Dialogue, 40(6), 617-636.

Peterson, M. (2005). Intelligence-Led Policing: The New Intelligence Architecture. Washington, DC: Bureau of Justice Assistance. U.S. Department of Justice.

Ratcliffe, J. H. (2008). Intelligence-Led Policing. Cullompton. Willan Publishing.

Ratcliffe, J. H., Strang, S. J., \& Taylor, R. B. (2014). Assessing the success factors of organized crime groups: Intelligence challenges for strategic thinking. Policing: An International Journal of Police Strategies and Management, 37(1), 206-227.

Ratcliffe, J. H., \& Walden, K. (2010). State police and the fusion center: A study of intelligence flow to and from the street. IALEIA Journal, 19(1), 1-19.

Rollins, J. (2008, January). Fusion centers: Issues and options for Congress. Washington, D.C.: Congressional Research Service. Report ADA482006.

Simic, M., Johnston, L. G., Platt, L. Baros, S. Andjelkovic, V. Novotny, T., \& Rhodes, T. (2006). Exploring barriers to 'respondent driven sampling' in sex worker and drug-injecting sex worker populations in Eastern Europe. Journal of Urban Health, 83(6), 6-15.

Taylor, R., \& Russell, A. (2012). The failure of police ‘fusion’ centers and the concept of a national intelligence sharing plan. Police Practice and Research, 13(2), 184-200.

U.S. Department of Homeland Security. (2011). Health Security: Public Health and Medical Integration for Fusion Centers. An Appendix to the Baseline Capabilities for State and Major Urban Area Fusion Centers. Washington, DC. U.S. Department of Justice. Global Intelligence Working Group.

U.S. Governmental Accountability Office. (2010). Information Sharing: Federal Agencies Are Helping Fusion Centers Build and Sustain Capabilities and Protect Privacy, but Could Better Measure Results. Washington, DC. Report to Congressional Requesters. Report GAO-10-972.

US House of Representatives. (2013). Majority Staff Report on the National Network of Fusion Centers. Washington, DC: Committee on Homeland Security.

U.S. Senate. (2012). Federal Support for and Involvement in State and Local Fusion Centers. Washington, DC: Permanent Subcommittee on Investigations. Committee on Homeland Security and Governmental Affairs. 


\section{Tables and Figures}

\section{Table 1. Fusion Centers Included in the Study $(n=74)$}

\section{Alabama Fusion Center}

Alaska Information and Analysis Center

Arizona Counter Terrorism Information Center

Arkansas State Fusion Center

Austin Regional Intelligence Center*

Boston Regional Intelligence Center*

California State Threat Assessment Center

Central California Intelligence Center*

Central Florida Intelligence Exchange*

Chicago Crime Prevention and Information Center*

Cincinnati/Hamilton County Regional Terrorism Early Warning Group*

Colorado Information Analysis Center

Connecticut Intelligence Center

Dallas Fusion Center*

Delaware Information and Analysis Center

Delaware Valley Intelligence Center*

Detroit and Southeast Michigan Information and Intelligence Center*

El Paso Multi-Agency Tactical Response Information Exchange*

Florida Fusion Center

Georgia Information Sharing and Analysis Center

Hawaii Fusion center

Houston Regional Intelligence Service Center*

Idaho Criminal Intelligence Center

Illinois Statewide Terrorism and Intelligence Center

Indiana Intelligence Fusion Center

Iowa Intelligence Fusion Center

Kansas City Terrorism Early Warning Fusion Center*

Kentucky Intelligence Fusion Center

Los Angeles Joint Regional Intelligence Center*

Louisiana State Analytical and Fusion Exchange

Maine Information and Analysis Center

Maryland Coordination and Analysis Center

Massachusetts Commonwealth Fusion Cente

Michigan Intelligence Operations Center

Minnesota Fusion Center

Mississippi Analysis and Information Center

Missouri Information Analysis Center
Montana All-Threat Intelligence Center

Nebraska Information Analysis Center

Nevada Threat Analysis Center*

New Hampshire Information and Analysis Center

New Jersey Regional Operations Intelligence Center

New Mexico All Source Intelligence Center

New York State Intelligence Center

North Carolina Information Sharing and Analysis Center

North Central Texas Fusion Center*

North Dakota State and Local Intelligence Center

Northeast Ohio Regional Fusion Center*

Northern California Regional Intelligence Center*

Northern Virginia Regional Intelligence Center*

Ohio Strategic Analysis and Information Center

Oklahoma Information Fusion Center

Orange County Intelligence Assessment Center*

Oregon Terrorism Information Threat Assessment Network

Pennsylvania Criminal Intelligence Center

Rhode Island State Fusion Center

San Diego Law Enforcement Coordination Center*

South Carolina Information and Intelligence Center

South Dakota Fusion Center

Southeast Florida Fusion Center*

Southeastern Wisconsin Threat Analysis Center*

Southern Nevada Counter-Terrorism Center

Southwest Texas Fusion Center*

Southwestern PA Region 13 Fusion Center*

St. Louis Fusion Center*

Tennessee Fusion Center

Texas Fusion Center

Utah Statewide Information and Analysis Center

Vermont Information and Analysis Center

Virginia Fusion Center

Washington Regional Threat and Analysis Center

Washington State Fusion Center

West Virginia Intelligence Fusion Center

Wisconsin Statewide Information Center

*Recognized fusion centers are marked with asterisks. Remaining centers are primary centers. 
Table 2. Fusion Center Survey Respondent Descriptives $(n=96)$

\begin{tabular}{lc}
\hline & $n$ (Valid Percent) \\
\hline Respondent's Position & \\
Administrator & $49(51 \%)$ \\
Supervisor & $19(20 \%)$ \\
Investigator & $7(8 \%)$ \\
Analyst & $10(10 \%)$ \\
Not Specified & $11(11 \%)$ \\
Respondent Years at Fusion Center & \\
Less than 1 Year & $10(10 \%)$ \\
1-3 Years & $39(41 \%)$ \\
4-9 Years & $26(27 \%)$ \\
More than 10 Years & $5(5 \%)$ \\
Not Specified & $16(17 \%)$ \\
\hline
\end{tabular}

Table 3. Sample Comparison

\begin{tabular}{lcc}
\hline Trait & $\begin{array}{c}\text { Web Content }(n=74) \\
n \text { (Valid Percent) }\end{array}$ & $\begin{array}{c}\text { Survey }(n=96) \\
n \text { (Valid Percent) }\end{array}$ \\
\hline $\begin{array}{l}\text { Fusion center Operational Focus } \\
\text { All-crimes, All-hazards, All- } \\
\text { threats }\end{array}$ & $41(55.4 \%)$ & $55(57.3 \%)$ \\
All-crimes & $31(41.9 \%)$ & $36(37.5 \%)$ \\
Terrorism & $2(2.7 \%)$ & $5(5.2 \%)$ \\
Main Operating Entity & & \\
State Police & $41(55.4 \%)$ & $55(57.3 \%)$ \\
Municipal Police & $10(13.5 \%)$ & $11(11.5 \%)$ \\
State Homeland Security & $8(10.8 \%)$ & $8(8.3 \%)$ \\
State Bureau of Investigations & $6(8.1 \%)$ & $7(7.3 \%)$ \\
County & $5(6.8 \%)$ & $8(8.3 \%)$ \\
HIDTA & $3(4.1 \%)$ & $3(3.1 \%)$ \\
Military & $1(1.4 \%)$ & $3(3.1 \%)$ \\
\hline
\end{tabular}


Figure 1. Fusion center Relationships for Information Sharing

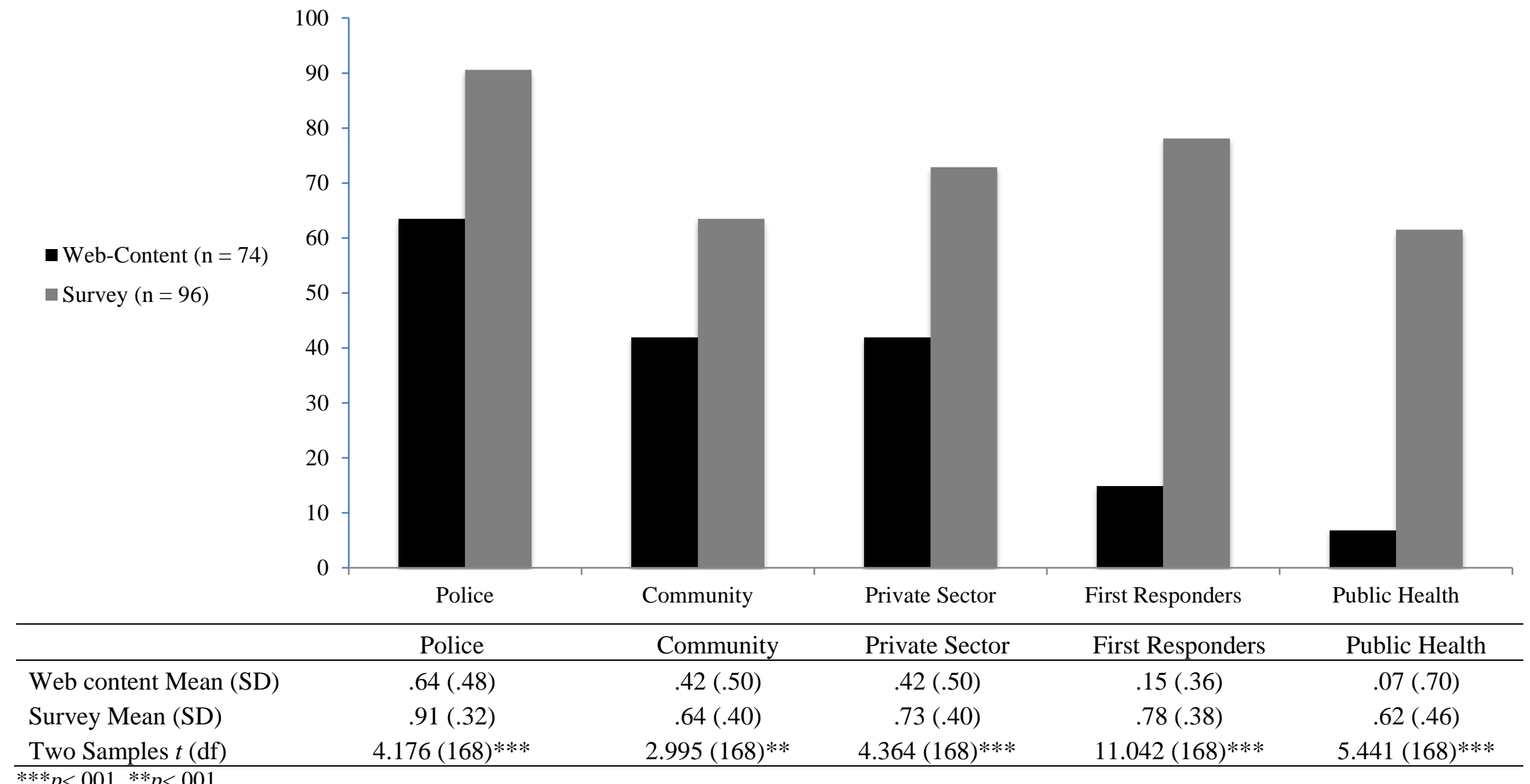




\section{Figure 2. Information Collection and Sharing}

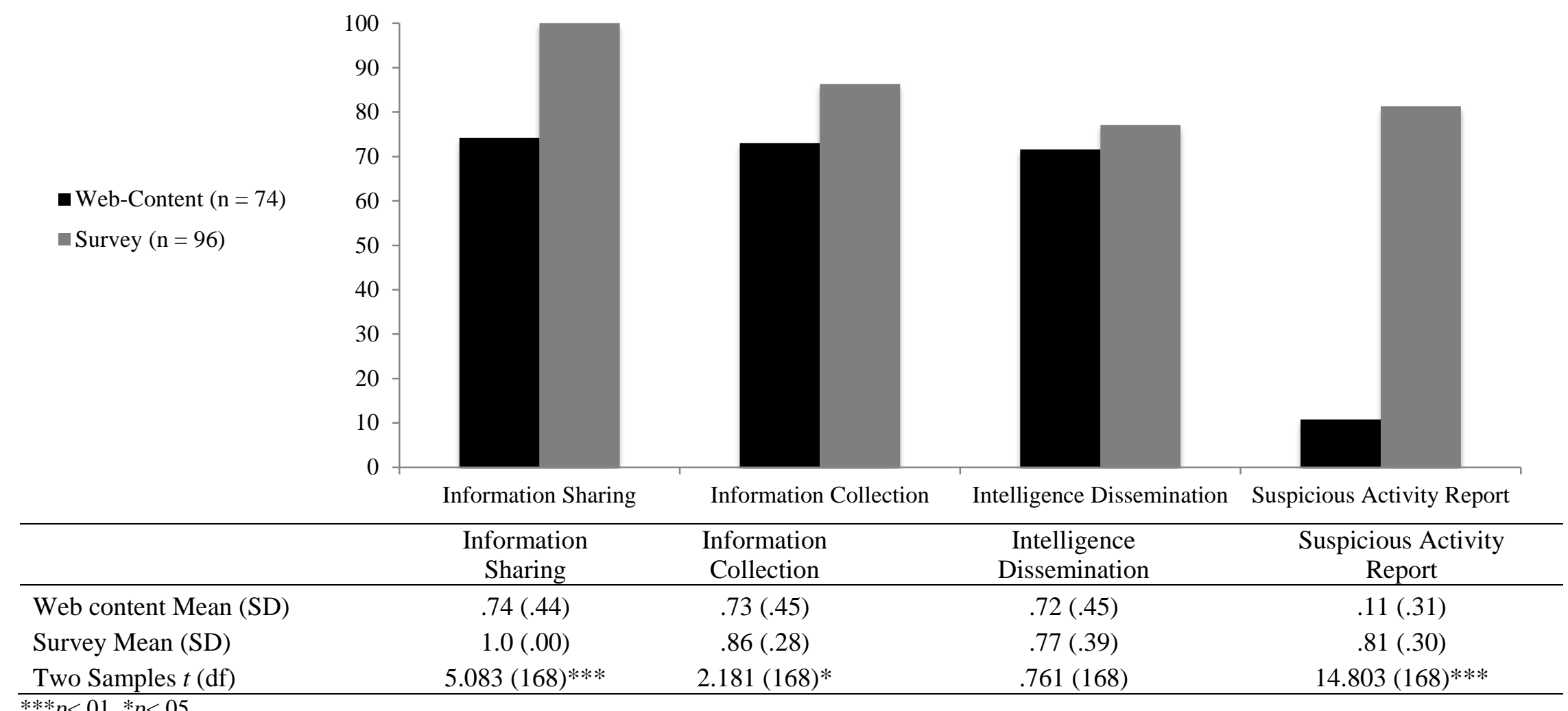


Figure 3. Analysis Properties

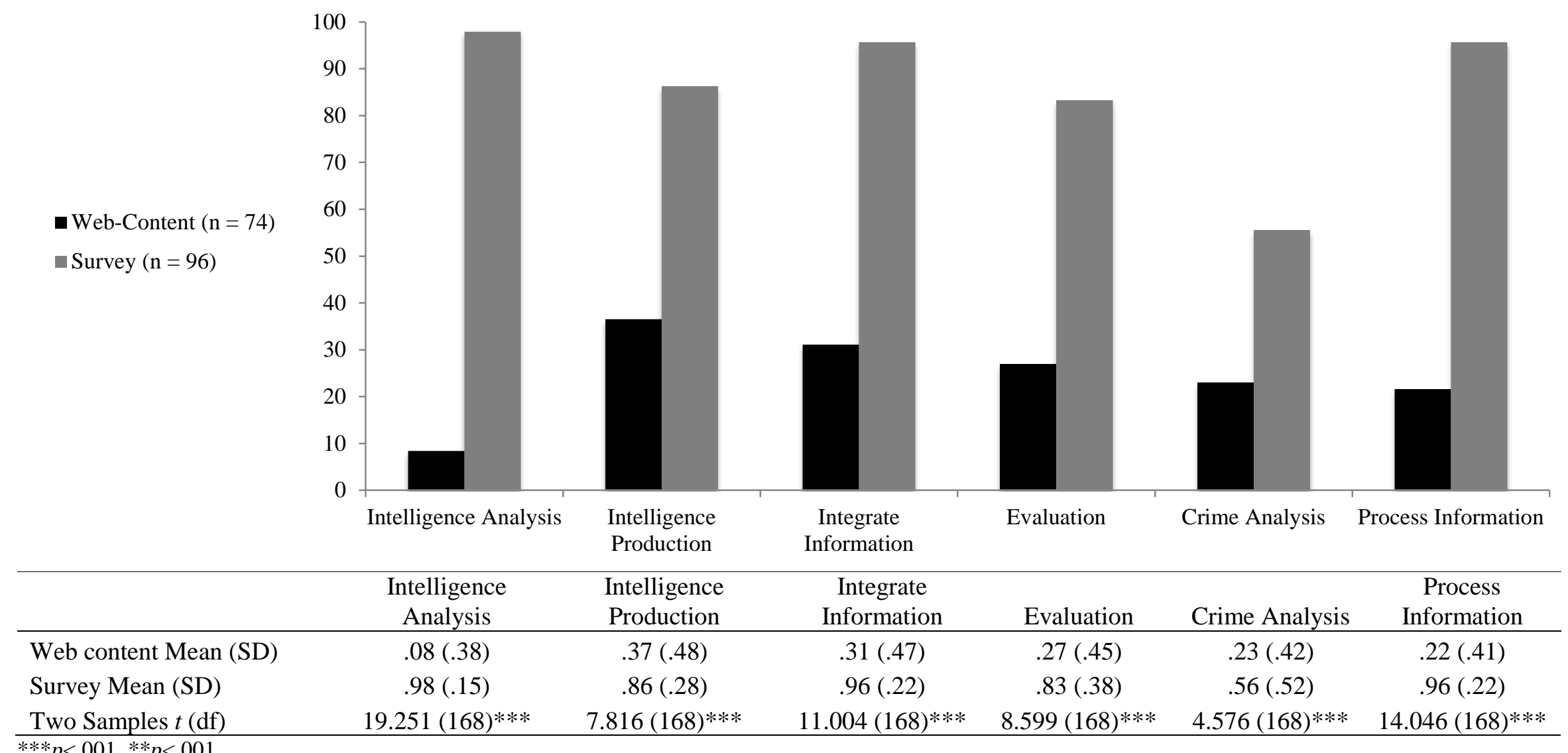


Figure 4. Areas of Emphasis

ש Web-Content (n = 74)

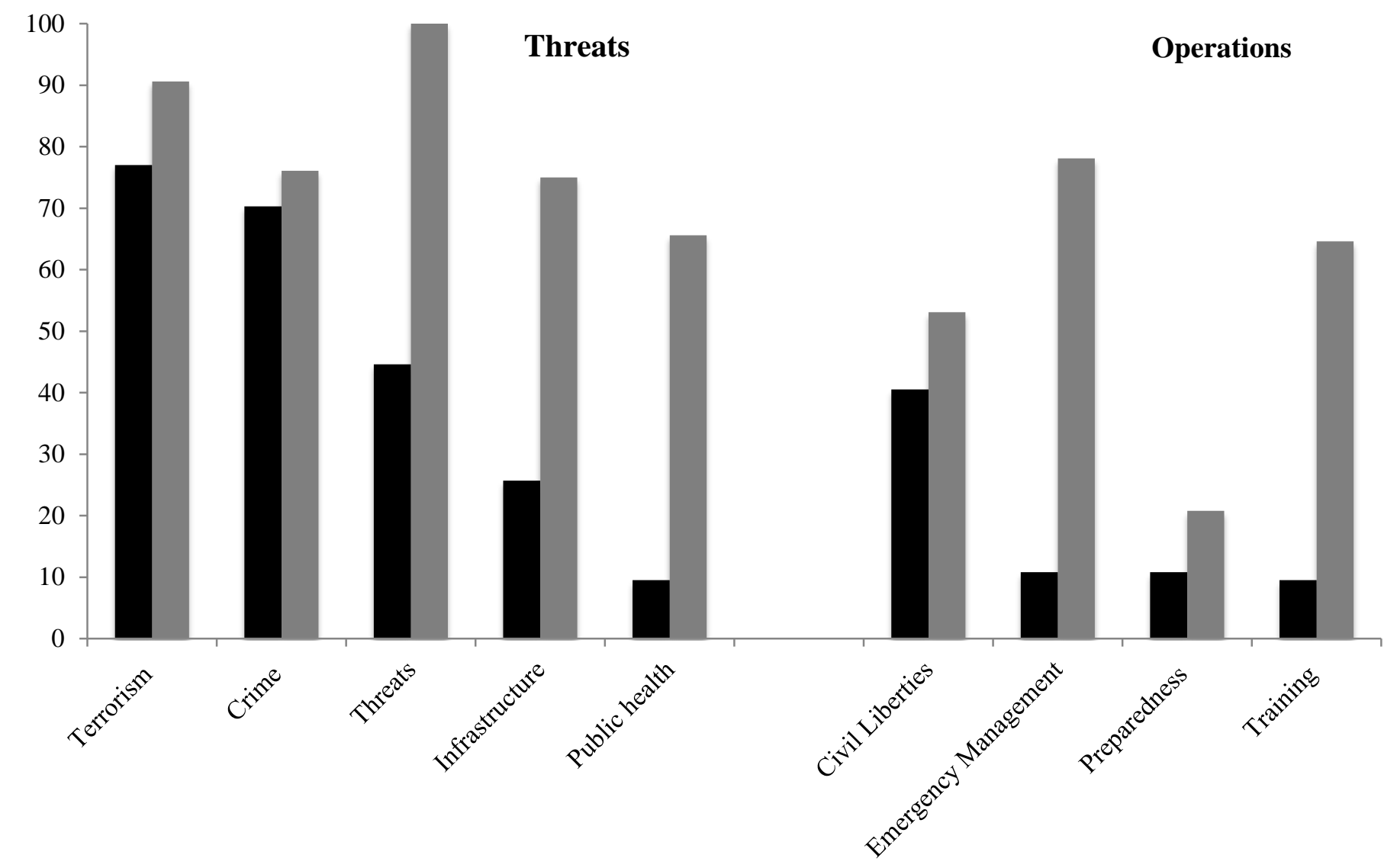

\begin{tabular}{|c|c|c|c|c|c|c|c|c|c|}
\hline & Terrorism & Crime & Threats & Infrastructure & Public Health & $\begin{array}{c}\text { Civil } \\
\text { Liberties }\end{array}$ & $\begin{array}{c}\text { Emergency } \\
\text { Management }\end{array}$ & Preparedness & Training \\
\hline Web content Mean (SD) & $.77(.42)$ & $.70(.44)$ & $.45(.50)$ & $.26(.44)$ & $.10(.29)$ & $.41(.49)$ & $.11(.31)$ & $.11(.31)$ & $.10(.29)$ \\
\hline Survey Mean (SD) & $.91(.28)$ & $.76(.40)$ & $1.0(.00)$ & $.75(.41)$ & $.66(.45)$ & $.53(.48)$ & $.78(.44)$ & $.21(.72)$ & $.65(.37)$ \\
\hline Two Samples $t(\mathrm{df})$ & $2.475(168)^{*}$ & $.917(168)$ & $9.463(168)^{* * *}$ & $7.415(168)^{* * *}$ & $9.829(168)^{* * *}$ & $1.597(168)$ & $11.636(168)^{* * *}$ & $1.222(168)$ & $10.865(168)^{* * *}$ \\
\hline
\end{tabular}

$* * * p<.01, * p<.05$ 